\title{
Vitamin and mineral supplementation and academic performance in schoolchildren
}

\author{
B Y MICHAEL NELSON \\ Department of Nutrition and Dietetics, King's College London, Campden Hill Road, \\ London W8 $7 A H$
}

Since the publication of Benton \& Roberts' (1988) article on the positive effects of multi-vitamin and mineral supplement on children's non-verbal intelligence, there has been a series of responses and counter-responses in the form of letters, learned opinions, and new research intended to clarify the relationship. After 4 years, there is still considerable doubt concerning the validity of this relationship in the UK (and, by implication, in other Western countries in which diets are by and large seen to be adequate).

There is no question that intelligence and academic performance are affected by nutritional status; evidence abounds from studies in undernourished children (Pollitt, 1990) and adults (Passmore \& Eastwood, 1986). What is in question is the level of undernutrition which must exist before academic performance in itself is affected, independent of other factors such as social and intellectual stimuli or the level of parental education. Those who find in favour of an effect of vitamin and mineral supplementation on intelligence in Western children suggest that the levels of nutrient intake, although sufficient to prevent the appearance of deficiency disease and equal to or above recommended dietary allowances (RDA), are below the levels required for 'optimal' functioning. Those who have failed to find beneficial effects of supplementation on IQ maintain that diets in the UK are more than adequate for the great majority of children, and that as the brain is a very selfish organ, it will sequester what it requires for optimal functioning, even at marginal levels of nutrition.

The purpose of the present paper is twofold: first, to review some of the evidence relating to the claim that vitamin and mineral supplementation is likely to improve IQ, particularly non-verbal intelligence, in a substantial proportion of children in developed countries; and second, to consider an experimental model that would help to resolve this question, and to re-analyse some existing data using the proposed model in order to re-test the hypothesis.

\section{THE DEBATE}

Benton \& Roberts (1988) published a paper purporting to show that a vitamin and mineral supplement, administered daily to a group of thirty 12-13-year-old Welsh schoolchildren over 8 months, produced a statistically significant increase in non-verbal IQ (but not verbal IQ) compared with a matched group receiving a placebo. The paper produced a flurry of responses (Bates et al. 1988; Bender, 1988; Emery et al. 1988; Hutton \& Ashby, 1988; MacFarlane, 1988; Macnair, 1988; Rose, 1988; Yudkin, 1988), the key elements of which argued that the reported dietary data (based on $3 \mathrm{~d}$ diaries) were unlikely to give a true picture of the dietary status of the children; that the supplement was not tailored to the subjects' apparent needs (e.g. low levels of iron, 
calcium, magnesium and iodine were reported, but the supplement contained only a small proportion of the RDA for these nutrients); and that the association between supplementation and non-verbal IQ was due, not so much to the increase in score in the treated group (an untreated group also increased their scores) but to an 'adverse' placebo effect, i.e. the failure of the placebo group to increase their scores when in practice the average score would be expected to increase on repeat administration of the tests.

Within 6 months, Naismith et al. (1988) had reported the results of a placebocontrolled intervention trial on 154 11-12-year-old children living in North London. The study differed from the Benton \& Roberts' (1988) study in the nature of the supplement (a specially made formulation which provided approximately $100 \%$ of the RDA for most micronutrients) and the length of its administration (28 d). The argument in this study was that any biochemical deficiencies in the brain which may have existed at the beginning of the study would have been rapidly put right by the supplement (within days, or at most, weeks). This argument was based on the concept that non-verbal, or 'fluid' intelligence, is more closely related to the biochemical functioning of the brain and, hence, would be likely to respond quickly to changes in the nutritional environment within the brain, as opposed to verbal, or 'crystallized' intelligence, which is based on accumulated knowledge. The study failed to show any significant effect of the supplement on non-verbal intelligence. Moreover, the authors (Nelson et al. 1990) later reported no statistically significant associations between initial IQ scores and estimates of nutrient intake (based on $7 \mathrm{~d}$ weighed records). This work was criticized on the grounds that it did not replicate the original study, and that the period of supplementation was too short to produce significant changes in IQ.

Crombie et al. (1990) published the results of an exact replication of the original Benton \& Roberts' (1988) study (same supplement, same time-period), but with improved dietary data. Like Naismith et al. (1988) they found no association of the supplement with changes in non-verbal IQ scores (even after controlling closely for compliance) and, like Nelson et al. (1990) they found no association between initial IQ scores and diet.

The response was a letter from Benton \& Buts (1990), not criticizing the Crombie et al. (1990) study, but reporting the results of a new trial assessing the effects of a multi-vitamin-mineral supplement on non-verbal IQ in a placebo-controlled trial in 167 Belgian children aged 13 years. Children completed $15 \mathrm{~d}$ diet diaries, and these were used to divide the children into 'better'- and 'poorer'-diet groups, 'poorer' being defined as a diet in which an individual's average intake over the $15 \mathrm{~d}$ fell below $50 \%$ of the 'RDA' for five or more nutrients (the source of the RDA was not specified). Average nutrient intake of the 'poorer'-diet group was typically about two-thirds that in the 'better'-diet group. The results showed that after 5 months of supplementation, in the 'better'-diet group, both the supplement and placebo produced similar increases in non-verbal IQ score, but in the 'poorer'-diet group, amongst the boys only, the supplemented group had a significant rise in non-verbal IQ (equal to the rise in the 'better'-diet group), while there was an adverse effect in the placebo group and scores fell. Of the girls in the 'poorer'-diet group, neither the supplement nor the placebo group showed an increase in non-verbal IQ scores. These inconsistent findings (one would expect to see a significantly greater gain in IQ scores of the supplemented children in the 'poorer'-diet group compared with the 'better'-diet group), and the appearance again of an adverse placebo effect, did little to clarify the relationship between IQ and 
vitamin-mineral supplementation in children from Western populations, although the attempt to classify children according to the adequacy of their diets was the first time that any analysis had been carried out which compared the effects of the supplement between groups in which the size of the benefits would be likely to differ.

Schoenthaler et al. (1991) reported the results of a study carried out in the United States on 410 children aged 12-13 or 15-16 years. Children were divided into four groups: control (placebo) and three supplemented groups receiving tablets containing either 50,100 , or $200 \%$ of the US RDA for thirteen vitamins, and amounts varying between 20 and $200 \%$ of the RDA (or not exceeding 'safe' levels) for ten minerals. The $100 \%$ tablet was identical in composition to the commercial preparation Vitachieve. There was no measure of diet, but blood was taken for biochemical analysis. After 13 weeks, the placebo, 50 and $200 \%$ groups showed similar increases in their non-verbal IQ scores $(8 \cdot 9,10 \cdot 1$ and 10.4 points respectively), but the $100 \%$ group showed a statistically significant increase (12.6 points). The results of this study are curious for at least two reasons. First, the authors can offer no plausible explanation of why the increase in scores in the $200 \%$ group was lower than in the $100 \%$ group. It is not credible to suggest that the $100 \%$ supplement provided exactly the right amount of nutrient to a group whose baseline diets would have varied considerably between individuals, and that $200 \%$ of the RDA was providing, as the authors suggest, 'an excess of selected nutrients impairing the digestion, absorption, and utilization of the other nutrients'. Second, the variation in results within the supplemented groups is little greater than in the placebo group. Statistically, this is an anomalous finding, as the increase in score, particularly in the $100 \%$ group (12.6 v. 8.9 points (placebo)) would be expected to be associated with a substantial increase in the amount of variation in the results, whereas the standard deviations for both groups were similar (placebo $7 \cdot 3,100 \%$ group $7 \cdot 9$ ). Other inconsistencies in the data and its presentation, and the failure to report the biochemical results, make the interpretation of the results difficult (Whitehead, 1991) and, therefore, does little to clarify the role of vitamin-mineral supplementation on children's IQ in Western populations.

Most recently, Benton \& Cook (1991) have reported the results of a placebocontrolled trial of 6-8 weeks vitamin-mineral supplementation in forty-seven 6 year olds. Diet was assessed by a food-frequency questionnaire (twenty-four items) completed by the parents. In this study, there was a statistically significant increase in non-verbal IQ due in part to an adverse placebo effect. The difference was present in girls but not in boys (the reverse of the Belgian study). Once again, the inconsistency of the results both within the study and in comparison with other studies makes a meaningful interpretation difficult.

Finally, Todman et al. (1991) have reassessed the findings of Crombie et al. (1990) in light of Underwood's (1975) theory that two tests supported by the same mental function should correlate, and that if there has been an intervention that genuinely affects that function, then on retesting, changes in the score on both tests should also correlate within individuals. In the Crombie et al. (1990) paper, two tests of non-verbal intelligence were administered, Calvert's DH and Heim's AH4 tests. The correlation between changes in score on the two tests was 0.19 in the supplemented group, and 0.28 in the placebo group $(P>0.05)$. By contrast, in a group similar in composition to those in the supplementation trial and to whom training on the tests was given, the correlation between changes in scores was $0.59(P<0.001)$. This lends further support to the 
Crombie et al. (1990) conclusion that the slightly greater increase of scores in non-verbal tests in the supplemented compared with the placebo group (difference by analysis of variance, $P>0.05$ ) was in fact part of normal statistical variation, and not suggestive of a trend.

\section{CONCLUSIONS FROM THE DEBATE}

From the work published to date, there is little to suggest that the diets of most Western children who are seen to be growing adequately are so deficient in micronutrients as to impair their mental functioning. The negative findings of the most carefully controlled studies (Naismith et al. 1988; Crombie et al. 1990; Nelson et al. 1990; Todman et al. 1991), and the anomalous and inconsistent findings from the other studies (Benton \& Roberts, 1988; Benton \& Buts, 1990; Schoenthaler et al. 1990; Benton \& Cook, 1991) do not support the hypothesis that a vitamin-mineral supplement, if widely distributed to adolescent or younger schoolchildren, would have a significant effect on the intelligence of the average child.

There is a nagging doubt, however, that within the UK there may be a sub-group of children whose diets are poor and who could, in theory, benefit from supplementation. This is not to say that supplementation is to be preferred to improvements in diet brought about by other means. Indeed, those children whose diets are least adequate are more likely to come from families which can least afford supplements. However, there may be evidence that poor nutritional status is associated with poorer performance on intelligence tests, and that improvements in performance could be associated with supplementation. Nelson et al. (1990) and Crombie et al. (1990) both failed to find an association between baseline diet and IQ, but their analyses were based on simple correlations and re-analysis of the data from Nelson et al. (1990) (see p. 308) provides limited evidence for this relationship in the UK. Certainly, there is abundant evidence from studies in Third World countries, amongst children with more pronounced nutrient deficiencies, to suggest that IQ and academic performance are associated with diet at baseline and are amenable to improvement through supplementation (Pollitt, 1990).

\section{A MODEL FOR EVALUATING THE EFFECTS OF SUPPLEMENTATION}

In the studies reported previously, the hypothesis is that in the UK and other Western countries, many children's diets are so deficient in nutrients that their mental functioning is affected; alternatively, the majority of children who are apparently well-nourished and growing well are nevertheless deficient in nutrients relating to mental function. The principal weakness of these hypotheses is the notion that the diets of the majority of children will be deficient with regard to mental functioning (attributed by Benton \& Roberts (1988) and Schoenthaler et al. (1991), for example, to the excess consumption of so-called 'junk' food), and the authors, therefore, fail to identify a sub-group of the sample with poorer nutritional status in whom the greatest benefits could be expected. Only the Belgian study by Benton \& Buts (1990) addressed this weakness, but the definitions of 'poorer' and 'better' diet were not related to other biochemical or clinical measures of nutritional status, nor to any observable changes in nutritional status following supplementation. 


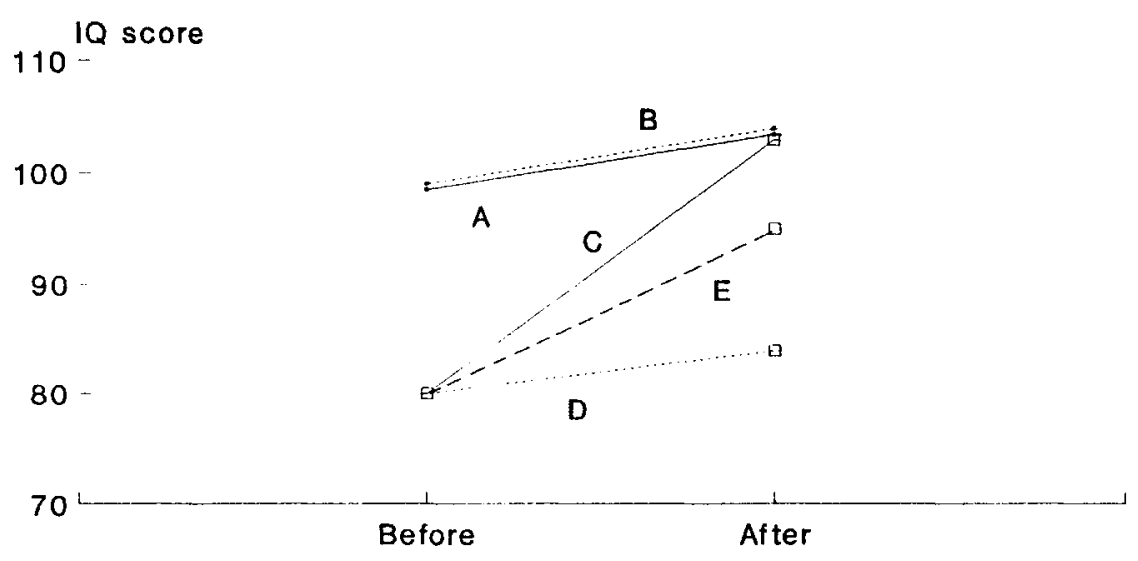

Fig. 1. Proposed model for investigation of the effects of vitamin-mineral supplements on IQ : expected effects (adapted from Fairchild et al. 1989). A, non-deficient, supplemented (-); B, non-deficient, placebo $(---)$; C, deficient, supplemented ( $\square-\square)$; D, deficient, placebo ( $\square--\square$ ); E, deficient, placebo, confounded by participation in experiment $(\square--\square)$.

In contrast to these vague hypotheses about inadequacy, several studies in the Third World have used precise definitions of inadequacy in relation to specific nutrient deficiencies, and have been able to demonstrate changes in both the intellectual and nutritional status of the children (Pollitt, 1990). Soemantri et al. (1985), for example, in assessing academic performance in relation to Fe deficiency and Fe supplementation used haemoglobin as a marker for Fe deficiency. Improvement in haemoglobin status on supplementation with Fe was used to identify a group for analysis who were regarded as having been truly $\mathrm{Fe}$ deficient at baseline. A group whose baseline haemoglobin classified them as non-anaemic was also given the Fe supplement to control for the effects on academic performance of being involved in the supplementation programme and, within both the anaemic and non-anaemic groups, children were randomly allocated in a double-blind fashion to either placebo or active treatment. This design is far more rigorous than any used in the studies reported in Western countries, and allows for (a) demonstration of an association between poor diet at baseline and lower IQ scores, (b) confirmation that the deficiency identified is dietary in origin and responds to supplementation, and (c) control for the effects of being involved in the programme. The model for such a design is illustrated in Fig. 1 (adapted from Fairchild et al. 1989) which shows the non-deficient children who would be expected to show a characteristic small increase in IQ score on re-testing regardless of whether they had received the active treatment (A) or the placebo (B). The deficient children, in whom there was clear evidence of lower IQ associated with poor nutritional status would be expected to show a marked improvement in scores following the supplement (C), but not if given the placebo (D). If involvement in the programme were an important confounder for improved performance then administration of the placebo could be associated with a significant increase in score $(\mathrm{E})$.

This model provides the best basis for testing the relationship between intellectual performance and supplementation in the UK and other Western countries. It requires 
rigorous assessment of nutritional and dietary status both before and after supplementation in order to demonstrate that any so-called deficiencies are indeed amenable to improvement through dietary supplementation.

\section{RE-EVALUATION OF THE RESULTS FROM NELSON ET AL. (1990)}

Although the study by Nelson et al. (1990) was not originally designed using the model described previously, it has been possible to re-analyse the data in order to simulate the model. Thus, deficient and non-deficient groups have been identified, the relationship between deficiency and baseline IQ scores assessed and the effects of supplementation on IQ tested in a placebo-controlled double-blind fashion in both the deficient and non-deficient groups.

Diet records $(7 \mathrm{~d})$ were used to classify children into deficient and non-deficient groups. As there were no biochemical measures of nutritional status, it was important in the re-analysis to identify those children whose records were most likely to represent their usual intakes. Goldberg et al. (1991) and Black et al. (1991) have discussed the evaluation of dietary records, and the need to acknowledge that low intakes in some subjects may simply represent poor recording rather than genuinely low intakes. They suggest that if the energy content of the recorded diet is compared with the basal metabolic rate (BMR; calculated from body-weight (Department of Health, 1991)), it would be unlikely that a subject whose recorded energy intake in any 1 week was less than 1.2 times BMR would be able to maintain energy balance, even taking into account the weekly variation in intake within individuals. Using this criterion, children were divided into good recorders and bad recorders. Of the seventy-six boys and sixty-seven girls whose results were reported previously (Nelson et al. 1990), fifty-three boys and forty-eight girls were classified as good recorders with an energy intake:BMR ratio of 1.2 or more. Table 1 shows that there were no differences between the ages, heights, or intelligence test results of the good and bad recorders. There were significant differences, however, between the good and bad recorders for BMI (as expected, those who were heavier were more likely to under-record) and for energy intake. The average energy intake:BMR ratio was 1.5 amongst the good recorders, and this agrees well with the expected values for normal levels of activity (Department of Health, 1991).

Having identified the good recorders and shown that they differed from the bad recorders only with respect to BMI and estimated energy intake but not in relation to intelligence, it was then appropriate to see if there was a relationship between intake and performance on the intelligence tests. Good recorders were, therefore, classified according to whether their intake of nutrient was less than the lower reference nutrient intake (LRNI), between the LRNI and the reference nutrient intake (RNI), or above the RNI (Department of Health, 1991) for ten vitamins (A, thiamin, riboflavin, niacin, pyridoxine, vitamin $\mathrm{B}_{12}$, folate, $\mathrm{C}, \mathrm{D}$ and $\mathrm{E}$ ) and four minerals $(\mathrm{Ca}, \mathrm{Fe}$, zinc and copper). (There is no LRNI given for vitamin $\mathrm{E}$ or $\mathrm{Cu}$, and these were estimated as 3 $\mathrm{mg} / \mathrm{d}$ and $0.6 \mu \mathrm{g} / \mathrm{d}$ respectively.) The distributions of good recorders between the three classes are shown in Fig. 2 ( $a$ and b) for boys and girls respectively; for thiamin, niacin, pyridoxine and $\mathrm{Cu}$ all the children had intakes near to or above the RNI, and for vitamin $\mathrm{D}$ all the children had intakes near to or below the LRNI, and the distributions for these nutrients are not shown. 
Table 1. Mean values for characteristics at baseline of good and bad diet recorders amongst 143 11-12-year-old North London schoolchildren, by gender*

(Energy intake:BMR $<1 \cdot 2$ bad, $>1 \cdot 2$ good)

\begin{tabular}{lcccc}
\hline \hline & \multicolumn{2}{c}{ Boys } & \multicolumn{2}{c}{ Girls } \\
\cline { 2 - 5 }$n \ldots$ & Bad & Good & Bad & Good \\
& 23 & 53 & 19 & 48 \\
\hline Age (years) & $12 \cdot 2$ & $12 \cdot 1$ & $12 \cdot 3$ & $12 \cdot 2$ \\
Height $(\mathrm{m})$ & $1 \cdot 50$ & $1 \cdot 47$ & $1 \cdot 53$ & $1 \cdot 52$ \\
Weight $(\mathrm{kg})$ & $49 \cdot 3$ & $38 \cdot 9$ & $49 \cdot 2$ & $45 \cdot 0$ \\
BMI $\left(\mathrm{kg} / \mathrm{m}^{2}\right)$ & $21 \cdot 8^{\mathrm{a}}$ & $17 \cdot 8^{\mathrm{b}}$ & $21 \cdot 0$ & $19 \cdot 3$ \\
Energy intake:BMR & $1 \cdot 0^{\mathrm{a}}$ & $1 \cdot 5^{\mathrm{b}}$ & $1 \cdot 1^{\mathrm{a}}$ & $1 \cdot 5^{\mathrm{b}}$ \\
Energy intake (kJ/d) & $6255^{\mathrm{b}}$ & $8385^{\mathrm{b}}$ & $6159^{\mathrm{a}}$ & $7958^{\mathrm{b}}$ \\
Percentage RDA for energy & $58^{\mathrm{a}}$ & $81^{\mathrm{b}}$ & $69^{\mathrm{a}}$ & $90^{\mathrm{b}}$ \\
Intelligence test scores & & & & \\
$\quad$ Verbal & $22 \cdot 3$ & $22 \cdot 0$ & $21 \cdot 3$ & $22 \cdot 9$ \\
Non-verbal & $37 \cdot 6$ & $36 \cdot 9$ & $38 \cdot 8$ & $40 \cdot 0$ \\
Digit span & $11 \cdot 0$ & $11 \cdot 3$ & $11 \cdot 4$ & $10 \cdot 6$ \\
Coding & $49 \cdot 9$ & $48 \cdot 2$ & $56 \cdot 0$ & $55 \cdot 3$ \\
\hline \hline
\end{tabular}

a,b Means with unlike superscript letters were significantly different (unpaired $t$ test; $P<0.001$ ).

BMR, basal metabolic rate; RDA, recommended dietary allowance.

* Data from Nelson et al. (1990).
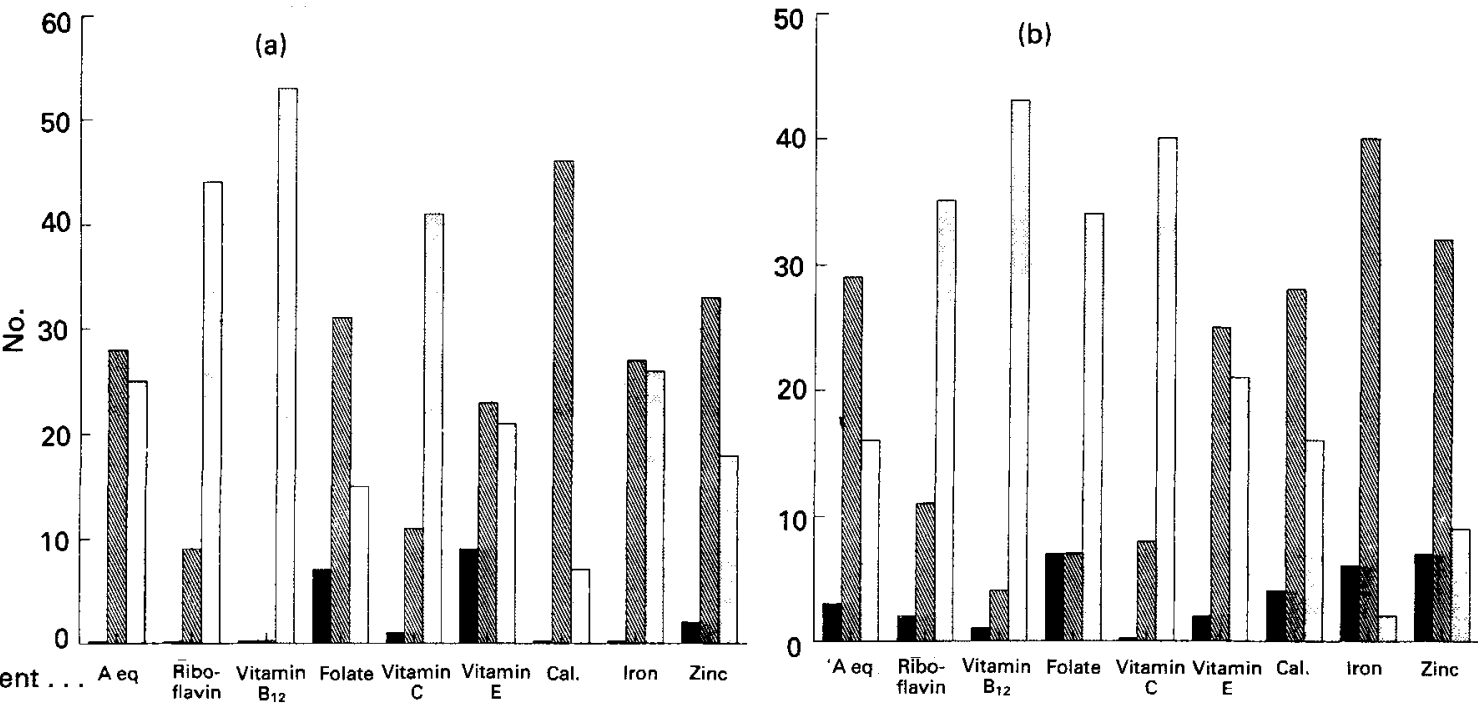

Fig. 2. Classification of nutrient intake of 11-12-year-old North London schoolchildren (a) boys, (b) girls classified as good recorders (for details, see p. 308), then further classified according to whether their intake of the nutrient was less than the lower reference nutrient intake (LRNI), between the LRNI and the reference nutrient intake (RNI), or above the RNI (Department of Health, 1991). (ם), <LRNI; (更 > LRNI, <RNI; (口), > RNI; A eq, retinol equivalent. (Data from Nelson et al. 1990.)

Using analysis of variance (controlling for gender), there were no statistically significant associations between the level of intake of any of the nutrients and the mean scores on any of the four intelligence test scores. There were, however, a very large 
Table 2. Index of intelligence test scores for six vitamins and three minerals at baseline and post-supplement for 11-12-year-old North London schoolchildren, by gender ${ }^{*}$

\begin{tabular}{lcccccc}
\hline & \multicolumn{2}{c}{ Baseline } & & \multicolumn{2}{c}{ Post-supplement } & \\
\cline { 2 - 3 } Nutrient & Boys & Girls & & Boys & Girls & Total \\
\hline Vitamin A & 4 & 2 & & 0 & 3 & 9 \\
Riboflavin & 3 & 2 & 2 & 6 & 13 \\
Vitamin B B & 0 & 2 & & 0 & 8 & 10 \\
Folic acid & 6 & 3 & 2 & 4 & 15 \\
Vitamin C & 6 & 4 & 3 & 2 & 15 \\
Vitamin E & 6 & 4 & 3 & 4 & 17 \\
Calcium & 2 & 1 & 2 & 9 & 14 \\
Iron & 5 & 5 & 2 & 6 & 18 \\
Zinc & 3 & 0 & 2 & 5 & 10 \\
\hline \hline
\end{tabular}

* Data from Nelson et al. (1990).

$\dagger$ For details of calculations, see below.

number of occasions for which the trend between intake and score was in the expected direction, i.e. low intake was associated with low mean scores and high intake with high mean scores, or, following supplementation, low initial intakes were associated with high mean changes in score, and high initial intakes were associated with low mean changes in score. It was tempting to believe that although the univariate analyses of intake $v$. intelligence test scores had not revealed any statistically significant associations, an analysis of the relationships between deficiencies of groups of nutrients and intelligence test scores might reveal some significant associations. An index was developed such that, for each nutrient, if the difference in intelligence test score means between the lowest and highest intake groups was not in the expected direction then a value of zero was assigned; if the difference in scores between the highest and lowest intake group was in the expected direction then a value of 1 was assigned; if the trend in scores was as expected across all three intake groups, a value of 2 was assigned. (No trend analysis was possible for thiamin, niacin, pyridoxine, vitamin $\mathrm{D}$ or $\mathrm{Cu}$.) The index was summed across five tests (verbal IQ, non-verbal IQ, total IQ, digit span and coding) at baseline and post-supplement by gender (the maximum sum of the index value in any one group was 10 ), and the results are shown in Table 2. When the index was summed across Table 2, folic acid, vitamins $\mathrm{C}$ and $\mathrm{E}$ and Fe had the highest totals. Children were classified as deficient if they had intakes below the LRNI for any of these four nutrients. Eleven boys and eleven girls were classified as deficient.

Table 3 shows the intelligence test scores at baseline for deficient and non-deficient children. The expectation was that the non-deficient children would have scores greater than those of the deficient children and, indeed, means were greater for the non-deficient children for verbal and non-verbal intelligence and for digit span (but not for coding). The difference in the means for the non-verbal test was statistically significant (analysis of variance controlling for gender, $P<0.05$ ). This significant result may have arisen because of the way in which deficient was defined (i.e. in terms of the associations with intelligence test scores), and it may also reflect confounding by social class or parental education, both of which might be associated with poorer diet and poorer scores. The 
Table 3. Mean intelligence test scores in 11-12-year-old North London schoolchildren, by gender, classified according to level of dietary adequacy $\dagger$ †

\begin{tabular}{|c|c|c|c|c|}
\hline \multirow[b]{2}{*}{$n \ldots$} & \multicolumn{2}{|c|}{ Boys } & \multicolumn{2}{|c|}{ Girls } \\
\hline & $\begin{array}{c}\text { Deficient } \\
11\end{array}$ & $\begin{array}{c}\text { Non-deficient } \\
42\end{array}$ & $\begin{array}{c}\text { Deficient } \\
11\end{array}$ & $\begin{array}{c}\text { Non-deficient } \\
37\end{array}$ \\
\hline \multicolumn{5}{|c|}{ Intelligence test } \\
\hline Verbal & $19 \cdot 6$ & $22 \cdot 5$ & $21 \cdot 1$ & $23 \cdot 5$ \\
\hline Non-verbal & $32.5 *$ & 37.9 & $36 \cdot 4^{*}$ & $41 \cdot 0$ \\
\hline Digit span & $10 \cdot 9$ & $11 \cdot 4$ & $10 \cdot 5$ & $10 \cdot 6$ \\
\hline Coding & $51 \cdot 7$ & $47 \cdot 3$ & $56 \cdot 5$ & 54.9 \\
\hline
\end{tabular}

Mean values were significantly different from those for non-deficient group (analysis of variance controlling for gender): $* P<0 \cdot 05$.

$\dagger$ Data from Nelson et al. (1990).

$\ddagger$ For details of classification, see p. 310 .

result cannot therefore, be taken as firm evidence of an association between diets which are low in these nutrients at baseline and non-verbal IQ. However, the result is robust in that it relates to the good recorders (whereas the previously published analysis related to all the children in the study), and it is interesting to note that S. Southon (personal communication) found a positive association between non-verbal intelligence scores and plasma levels of ascorbic acid and glutathione peroxidase (EC 1.11.1.9) activity (a reaction which is dependent on selenium and, indirectly, on vitamin $E$ levels).

The second expectation was that the deficient children would increase their test scores more than the non-deficient children following supplementation. The results in Table 4 show that the mean change in score was significantly greater amongst the deficient children for verbal intelligence in boys only $(P<0.05)$ and for non-verbal intelligence in girls only $(P<0 \cdot 01)$. Within the deficient group, however, the mean change in non-verbal IQ score (increase of 10 points in boys plus girls) was the same on active supplement and placebo. The average increase in score amongst the non-deficient children was 7 points on both active treatment and placebo. These changes suggest a regression to the mean effect (i.e. those with lower initial scores would be expected to show a greater improvement on re-testing). There is no evidence, therefore, that the supplement has had a beneficial effect on the children's non-verbal IQ scores.

This re-analysis suggests that there may be a group of children whose diets are deficient with regard to several nutrients, and that these diets are associated with poorer performance on a non-verbal IQ test. It does not imply a causal relationship, however, as there are several possible confounders. Where there is the suggestion of an association between supplementation and improved performance, the results are not consistent between boys and girls, nor between tests, and when averaged over both sexes, show no differences in the amount of change in IQ score between the active and placebo groups. The re-analysis does not, therefore, support the conclusion that amongst UK adolescents, vitamin-mineral supplementation is of value in improving IQ scores, even in a group of children identified at baseline as deficient. 
Table 4. Mean change in intelligence test scores in 11-12-year-old North London schoolchildren, by gender, classified according to level of dietary adequacy and type of supplement given $\dagger \ddagger$

\begin{tabular}{|c|c|c|c|c|c|}
\hline \multirow[b]{2}{*}{$n$. } & & \multicolumn{2}{|c|}{ Boys } & \multicolumn{2}{|c|}{ Girls } \\
\hline & & $\begin{array}{c}\text { Deficient } \\
11\end{array}$ & $\begin{array}{c}\text { Non-deficient } \\
42\end{array}$ & $\begin{array}{c}\text { Deficient } \\
11\end{array}$ & $\begin{array}{c}\text { Non-deficient } \\
37\end{array}$ \\
\hline $\begin{array}{l}\text { Intelligence te } \\
\text { Verbal }\end{array}$ & $\begin{array}{c}\text { Mean } \\
\text { P } \\
\text { A }\end{array}$ & $\begin{array}{l}7 \cdot 6^{*} \\
6 \cdot 8 \\
8 \cdot 5\end{array}$ & $\begin{array}{l}3 \cdot 7 \\
3 \cdot 2 \\
4 \cdot 0\end{array}$ & $\begin{array}{r}5 \cdot 3 \\
11 \cdot 5 \\
3 \cdot 9\end{array}$ & $\begin{array}{l}6 \cdot 1 \\
7.2 \\
4.7\end{array}$ \\
\hline Non-verbal & $\begin{array}{c}\text { Mean } \\
\text { P } \\
\text { A }\end{array}$ & $\begin{array}{l}7.2 \\
7.6 \\
6.8\end{array}$ & $\begin{array}{l}7 \cdot 0 \\
5 \cdot 0 \\
8 \cdot 4\end{array}$ & $\begin{array}{l}12 \cdot 6^{* *} \\
17 \cdot 0 \\
11 \cdot 7\end{array}$ & $\begin{array}{l}6.8 \\
7.8 \\
5.6\end{array}$ \\
\hline Digit span & $\begin{array}{c}\text { Mean } \\
\text { P } \\
\text { A }\end{array}$ & $\begin{array}{r}-0.2 \\
0.8 \\
-1.0\end{array}$ & $\begin{array}{l}1 \cdot 2 \\
1 \cdot 2 \\
1 \cdot 2\end{array}$ & $\begin{array}{r}0.1 \\
-0.5 \\
0.2\end{array}$ & $\begin{array}{l}0.6 \\
1.0 \\
01\end{array}$ \\
\hline Coding & $\begin{array}{c}\text { Mean } \\
\text { P } \\
\text { A }\end{array}$ & $\begin{array}{l}6 \cdot 0 \\
4 \cdot 2 \\
7.5\end{array}$ & $\begin{array}{l}7 \cdot 2 \\
9 \cdot 1 \\
5 \cdot 9\end{array}$ & $\begin{array}{r}8.8 \\
11.0 \\
8.3\end{array}$ & $\begin{array}{l}7.6 \\
7.5 \\
7.8\end{array}$ \\
\hline
\end{tabular}

$\mathrm{P}$, placebo; A, active.

Mean values were significantly different from those for non-deficient group (unpaired $t$ test): $P<0 \cdot 05$, $* * P<0-01$.

$\dagger$ Data from Nelson et al. (1990).

$\ddagger$ For details of classification, see p. 310 .

\section{CONCLUSIONS}

It is clear from Third World studies that vitamin-mineral supplementation of schoolchildren with well-characterized nutritional deficiencies can produce consistent and significant improvements in performance on intelligence tests, independent of any improvements which might relate to being involved in the study (for example, increased stimulation and performance as a result of increased contact with adults). The mechanisms whereby these improvements occur need elucidating.

In Western countries, there may be a proportion of children whose diets are poor, and whose poorer performance on IQ tests could theoretically be due to marginal nutrient deficiencies, independent of the effects of social class, parental education, or other confounding factors. Evidence for such an association is weak, however. There are no consistent results to suggest that vitamin-mineral supplementation would be of value in improving their performance on IQ tests.

If this area of research is to be pursued, then properly designed studies must identify children who are nutrient deficient (using both dietary and biochemical assessments), and use a double-blind placebo-controlled intervention in both deficient and nondeficient children to assess the effects of vitamin-mineral supplementation on both nutritional status and intelligence. Only in this way will we be able to determine the scale of any benefit that can be expected from vitamin-mineral supplementation amongst Western children, the large majority of whom, by current standards, can be regarded as well-nourished. 


\section{REFERENCES}

Bates, C. J., Thurnham, D. I. \& Powers, H. J. (1988). Vitamin/mineral supplementation and non-verbal intelligence (letter). Lancet i, 407.

Bender, D. (1988). Vitamin/mineral supplementation and non-verbal intelligence (letter). Lancet i, 409.

Benton, D. \& Buts, J. P. (1990). Vitamin/mineral supplementation and intelligence. Lancet 335, 1158-1160.

Benton, D. \& Cook, R. (1991). Vitamin and mineral supplements improve the intelligence scores and concentration of six-year-old children. Personal and Individual Differences 12, 1551-1558.

Benton, D. \& Roberts, G. (1988). Effect of vitamin and mineral supplementation on intelligence of a sample of schoolchildren. Lancet i, 140-143.

Black, A. E., Goldberg, G. R., Jebb, S. A., Livingstone, M. B. E., Cole, T. J. \& Prentice, A. M. (1991). Critical evaluation of energy intake data using fundamental principles of energy physiology: 2. Evaluating the results of published surveys. European Journal of Clinical Nutrition 45, 583-599.

Crombie, I. K., Todman, J., McNeill, G., du V. Florey, C., Menzies, I. \& Kennedy, R. A. (1990). Effect of vitamin and mineral supplementation on verbal and non-verbal reasoning of schoolchildren. Lancet 335, 744-747.

Department of Health. (1991). Dietary Reference Values. London: H.M. Stationery Office.

Emery, P. W., Nelson, M., Geissler, C. G., Sanders, T. A. B., Judd, P. A., Thomas, J. E. \& Naismith, D. J. (1988). Vitamin/mineral supplementation and non-verbal intelligence (letter). Lancet $\mathbf{i}, 407$.

Fairchild, M. W., Haas, J. D. \& Habicht, J.-P. (1989). Iron deficiency and behavior: criteria for testing causality. American Journal of Clinical Nutrition 50, 566-574.

Goldberg, G. R., Black, A. E., Jebb, S. A., Cole, T. J., Murgatroyd, P. R., Coward, W. A. \& Prentice, A. M. (1991). Critical evaluation of energy intake data using fundamental principles of energy physiology: 1. Derivation of cut-off limits to identify under-recording. European Journal of Clinical Nutrition 45, 569-581.

Hutton, J. L. \& Ashby, D. (1988). Vitamin/mineral supplementation and non-verbal intelligence (letter). Lancet $\mathbf{i}, 407$.

MacFarlane, A. (1988). Vitamin/mineral supplementation and non-verbal intelligence (letter). Lancet i, 408.

Macnair, A. (1988). Vitamin/mineral supplementation and non-verbal intelligence (letter). Lancet i, 407-408.

Naismith, D. J., Nelson, M., Burley, V. J. \& Gatenby, S. J. (1988). Can children's intelligence be increased by vitamin and mineral supplements? Lancet ii, 335.

Nelson, M., Naismith, D. J., Burley, V., Gatenby, S. \& Geddes, N. (1990). Nutrient intakes, vitamin-mineral supplementation and intelligence in British schoolchildren. British Journal of Nutrition 64, 13-22.

Passmore, R. \& Eastwood, M. A. (1986). Davidson and Passmore Human Nutrition and Dietetics. London: Churchill Livingstone.

Pollitt, E. (1990). Malnutrition and Infection in the Classroom. Paris: UNESCO.

Rose, G. A. (1988). Vitamin/mineral supplementation and non-verbal intelligence (letter). Lancet i, 408.

Schoenthaler, S. J., Amos, S. P., Eysenck, H. J., Peritz, E. \& Yudkin, J. (1991). Controlled trial of vitamin-mineral supplementation: effects on intelligence and performance. Personal and Individual Differences 12, 351-362.

Soemantri, A. G., Pollitt, E. \& Kim, I. (1985). Iron deficiency anaemia and educational achievement. American Journal of Clinical Nutrition 42, 1221-1228.

Todman, J., Crombie, I. \& Elder, L. (1991). Personal and Individual Differences 12, 1333-1337.

Underwood, B. J. (1975). Individual differences as a crucible for theory construction. American Psychologist 30, 128-134.

Whitehead, R. G. (1991). Vitamins, minerals, schoolchildren and IQ. British Medical Journal 302, 48.

Yudkin, J. (1988). Vitamin/mineral supplementation and non-verbal intelligence (letter). Lancet i, 407. 